\title{
La paradoja de la estupidez ${ }^{1}$
}

\section{Antonio Gómez Ramos*}

\section{Resumen}

Este ensayo explora la relación entre el fenómeno de la estupidez y la construcción de la subjetividad en el proceso formativo de la educación. A partir de la lectura de dos ensayos clásicos sobre la estupidez, el de Robert Musil y el de Eduard Erdmann, se establece el carácter paradójco de la estupidez. Por un lado equivale a la incapacidad para adoptar puntos de vista distintos del propio, y, en esa medida, puede ser corregida por el proceso de la Bildung, de la adquisición de la facultad de juzgar y, con ello, de la formación de una subjetividad propia. El Juicio, sobre todo, que requiere precisamente de esos puntos de vista ajenos, tal como se muestra, con notables implicaciones políticas y críticas, en la obra de Hannah Arendt y en la tercera crítica de Kant. Por otro lado, la estupidez es un concepto práctico de las relaciones intersubjetivas que responde a la opacidad de las conductas ajenas; pero, también, y sobre todo, la estupidez da cuenta del núcleo más íntimo e irreductible de cada subjetividad: aquel que no puede ser recogido por ningún juicio. La estupidez tiene así una relación paradójica en la constitución de los sujetos, y a esa paradoja debe atender la educación.

Palabras clave: Subjetividad. Educación. Estupidez. Bildung.

"Contra la estupidez, los dioses mismos luchan en vano"; frente a esta antigua frase, que testifica con fatalidad de lo irremediable de la condición humana, está la convicción de que los sujetos individuales son, de alguna manera, mejorables. La convicción de que los seres humanos pueden mejorar gracias a la educación, la cual los puede arrancar de la tosquedad y la inconsciencia para hacer de ellos seres autónomos y maduros, responsables de su vida. La educación puede hacer de un niño un ciudadano adulto, de un analfabeto alguien que pueda vivir en el mundo de la palabra escrita y de la cultura, puede fomentar y modelar las capacidades racionales de todas las personas: es por ella que somos más inteligentes, más cultos, más cívicos. Y, sobre todo ayuda a cada uno a ser más sí-mismo. Pero, ¿puede ayudarnos a ser menos estúpidos, o al menos, a dejar de cometer estupideces? ¿Puede conseguir lo que los dioses mismos no pueden? Este ensayo quiere explorar la res- 
puesta a esa pregunta. Veremos que, a la vez que hay una relación inversa entre la estupidez y la formación, aquella pertenece tan peculiarmente a la subjetividad humana que una teoría de la educación no puede dejar de asumirla.

Hay, de hecho, pocos ensayos sobre la estupidez, si se compara su número con los que se han escrito sobre la razón y la inteligencia humana. Puede que no falte lógica en ello, dado que somos con más frecuencia estúpidos que lo contrario, y se tiende más bien a escribir sobre lo que no se tiene que sobre lo que se tiene. Pero, aparte de que estupidez y racionalidad podrían no ser cualidades contrarias, como veremos, la razón de la escasa atención que la estupidez ha merecido puede encontrarse en otro sitio. $\mathrm{Y}$ es que no se puede hablar sobre la estupidez sin sentirse incómodo. Es una incomodidad de la que el autor se alivia enseguida recurriendo a alguna ironía que le permita afirmarse en su discurso a la vez que se degrada cómicamente a sí mismo. En los ensayos sobre la estupidez, el autor se apresura a despojarse de toda arrogancia aparente declarando que él mismo no se tiene por menos estúpido que los demás, y que es consciente de lo riesgoso de su asunto. ¿Quién puede hablar sobre la estupidez sin mirar hacia sí mismo por un momento, sin aclarar de algún modo su situación respecto a ella? Se ve ya aquí que la estupidez misma concita un gesto de necesaria ironía y, por ende, una relación de autorreflexividad, que forma parte de la condición subjetiva de la que, en definitiva, trata toda educación. Tal vez por eso, la estupidez sea, en contra de lo que podría esperarse inicialmente, una vía bien directa para acercarse a definir la subjetividad o mismidad, por más que el sujeto, en tanto que humano, se pretenda constituir sobre sus capacidades racionales y su capacidad para formarse y educarse, para alcanzar cierta sabiduría. Así es, seguramente, pero ese proceso de constitución son ajenos acciones y fenómenos que, de un modo paradójico, se derivan de eso que llamamos estupidez.

Lo primero que llama la atención de la estupidez es que es indefinible, a pesar de la claridad con la que parecemos identificarla. Contrasta la firmeza con la que aplicamos en la práctica el apelativo de estúpido frente a las dudas que nos paralizan a la hora de establecer teóricamente un concepto de estupidez. Esta certeza práctica frente a la indefinición teórica es la causa, probablemente, de que se trate a la estupidez más con ejemplos que con conceptos, y de que la historia del pensamiento haya producido sobre ella más una serie de ensayos salpicados de anécdotas cómicas, por estúpidas, que un tratado sobre lo estúpido. Que yo sepa, no se ha producido ninguno, aunque sí algunos ensayos muy inteligentes, dos de los cuales nos servirán de guía en este primer capítulo. ${ }^{2}$ 
La principal razón por la que la estupidez no es definible es que ella misma no constituye un objeto como tal. Más que la estupidez, lo que encontramos son situaciones o actuaciones de personas que calificamos de estúpidas -y, además, lo hacemos de un modo casi inmediato-, siendo difícil encontrar en todas ellas un rasgo común, o siquiera un conjunto de características definible que diera un cierto aire de familia. En general, está muy relacionada con el contexto, y la actuación que en un contexto podría ser considerada inteligente, en otro, literalmente igual, resultaría estúpida. De hecho, hablamos de situaciones estúpidas - y, en general, con una exclamación-, pero nunca diríamos de una situación que es "inteligente". Ya esto nos hace ver que la estupidez no es lo contrario de la inteligencia, ni tampoco la ausencia de ella. Con cierto humor - el humo, que es inevitable para hablar de estas cosas -, Mathias Van Boxsel comienza su Enciclopedia de la estupidez diciendo que

[...] nadie es lo bastante inteligente como para llegar a comprender la medida de su propia estupidez. La inteligencia y la estupidez no son lo contrario una de la otra, ni la estupidez es la falta de inteligencia, sino que la inteligencia es el producto, mas o menos fracasado, de una serie continuada de intentos para dominar, o escapar, a la estupidez constitutiva de todo lo humano (2003, p. 60).

La idea de que la estupidez es lo original, mientras que lo que llamamos inteligencia es más bien lo derivado o secundario, guarda cierta concordancia, aunque en una modulación exagerada, con nuestra intuición inicial de que el fenómeno de la estupidez está muy dentro de lo subjetivo y de la relación con uno mismo; pero no es eso lo que importa ahora. Más bien se trata, sobre todo, de que hay una sustancia de lo estúpido que lo hace independiente de la inteligencia, y por la que no es ni lo contrario ni una cantidad disminuida de esta - un poco como, quizá, el mal no sea lo contrario del bien, ni la ausencia de este, sino algo que se sostiene por sí mismo. Así, independiente de la inteligencia, la estupidez se aparece como algo inescapable que se puede dar por todas partes y en todas las situaciones. Desde luego, se da acompañando muchas veces a la inteligencia más sofisticada; e incluso, a menudo, de un modo casi necesario. Esto puede parecer sorprendente, pero ocurre de formas bien variadas. En primer lugar, es perfectamente posible ser muy inteligente y ser a la vez un estúpido que nunca ha pensado nada - como veremos luego a propósito de Hannah Arendt, cuando abordemos de lleno la paradoja de la estupidez. Es el caso, por ejemplo, de la aguda inteligencia que comprende una alta capacidad de penetración cognitiva y de eficacia en la acción, pero que va acompañada de lo que podríamos llamar "idiotez moral". O es el caso, un tipo particular del anterior, de lo que los alemanes llaman un Fachidiot, ese especialista que únicamente es capaz de ver y juzgar el mundo con las estrechas y sofisticadas lentes de su especialidad, que él domina, quizá, gracias a un coeficiente de inteligencia superior. 
Pero, en segundo lugar, la relación entre inteligencia y estupidez está determinada por el hecho de que el riesgo de comportarse como un estúpido tiene mucho que ver con el modo de administrar la relación de uno mismo con su propia inteligencia, y su presentación ante los demás. Está la vanidad, por ejemplo, ese caso de estupidez en la que cae el hombre inteligente que no se resiste a hacer gala de ello. De hecho, como concluye Musil tras hacer unas consideraciones sobre este punto, "es estúpido hacer gala de inteligencia; no es inteligente ganarse fama de estúpido" (2007, p. 61). No lo es, y sin embargo, como en todo lo que tiene que ver con cualidades ligadas al contexto, la valoración puede invertirse enseguida, y hay situaciones en las que lo inteligente es precisamente pasar por estúpido, hacerse el tonto (más de uno ha salvado el pellejo de esa manera, y no sin mérito, pues fingir la estupidez puede ser tan difícil como fingir la inteligencia). Y también puede haber situaciones en las que lo inteligente sea (parecer estúpido por) hacer gala de inteligencia: pero, entonces, claro, la inteligencia que se tiene no es aquella de la que se hace gala. Una vez que las cualidades dependen del contexto, las posibilidades son ilimitadas.

Todos estos rodeos y tentativas para acercarse al fenómeno de la estupidez no nos aclaran todavía mucho acerca de ella y de cómo puede ser contribuir a elucidar la noción de subjetividad, pero empiezan a poner de manifiesto, cuando menos, que la estupidez va ligada al trato con los otros y con nosotros mismos. Con nosotros mismos, en tanto que la reconocemos en nosotros: y parece que, en paralelo con la docta ignorantia socrática, la reconocemos mejor en tanto que somos inteligentes; incluso que hay una inteligencia en el modo de guardar, reconocer, o dejar ver lo estúpido que uno es. $\mathrm{Y}$ en el trato con los otros, en tanto que la estupidez la predicamos mayormente de otras personas, a las que, no sabemos por qué, pero con certeza irrefrenable, denominamos estúpidas; o la predicamos de situaciones en las que se ven envueltas las personas. A veces, incluso, personas que podríamos llamar con justicia inteligentes.

De hecho, la estupidez, que se predica de personas individuales ${ }^{3}$, nace, sin embargo, en condiciones de intersubjetividad. Dejando al margen las dificultades de la relación con la propia estupidez, lo cierto es que, de partida, la estupidez es un problema de otros: los estúpidos son los otros. Lo importante no es aquí el habitual desplazamiento hacia los otros de todo lo desagradable (el infierno son los otros, los mafiosos son los otros, etc.), sino la circunstancia, mucho más decisiva, de que ese concepto práctico que denominamos estupidez funciona, sobre todo y en primer lugar, como un insulto. De hecho, el calificativo de "estúpido" no se utiliza primariamente para describir a otra persona, sino que se profiere como reacción ante una actitud o actuación del otro que nos desespera y descoloca. La pura racionalidad no 
insulta - no dice "¡estúpido! - sino que describe y caracteriza neutralmente al otro. Es justamente cuando no somos capaces de dar una descripción racional y objetiva, cuando no sabemos qué decir porque el otro nos ha descolocado, o nos ha deshecho el esquema explicativo con el que nos acercamos a él, cuando recurrimos a esa mezcla de representaciones, sentimientos e intenciones que no se saben expresar de otra manera más que como insulto. Por supuesto, hay muchas modalidades de insulto, y hay toda una teoría y arte de la injuria; pero, en ella, "estúpido" señala seguramente el nivel más bajo de descripción, y es la palabra más pobre. También, por cierto, la más inocua: no sirve para una calumnia.

El insulto "estúpido" se pronuncia cuando no se tiene un juicio formado. En realidad, cualquier otro insulto más sofisticado contiene algún modo de crítica, alguna elaboración del juicio acerca del otro, incluso si es tosca, por más que su voluntad de ofender desvirtúe lo que pueda tener de verdadero (en tanto que describa ajustadamente al otro). El insulto "estúpido" es, en cambio, por decirlo con Musil, una "crítica desarticulada", en la que se siente que algo está mal, pero no se logra identificar qué es. Por eso, justamente, podemos llamar estúpido a cualquiera: no así mafioso, corrupto, pervertido, o cualquier otra en la que se pueda pensar. Como todo insulto, la exclamación "estúpido" no deja de ser una reacción de pánico, esta vez ante lo inexplicable del otro, ante su resistencia a encasillarse en nuestra imagen previa establecida de él o del mundo. Y como en toda reacción de pánico, el sujeto que la tiene esta tanto o más afectado que el objeto que la produce, de manera que el sujeto se ve alcanzado por la estupidez del objeto, en este caso, la otra persona, a quien insulta. Al fin y al cabo, la incomprensión que produce en nosotros aquel al que llamamos estúpido nos deja igualmente sometidos al estupor del que no comprende, estupefactos: nos deja estúpidos también a nosotros. Si fuéramos suficientemente racionales y sabios, si tuviéramos una explicación para su conducta, no llamaríamos al otro estúpido: lo describiríamos de manera neutral, una vez que lo hubiéramos comprendido. ${ }^{4}$ Puede que la estupidez se contagie como un virus, como a veces se dice, y vaya pasando de uno a otro de los participantes en una situación; pero el fenómeno más originario es que la estupidez se produce a la vez, simultáneamente, en el sujeto que causa la exclamación y en el sujeto que la exclama. La incomprensión de éste hacia su objeto le hace preguntarse, muchas veces (suponiendo, claro está, un grado mínimo de honestidad): ¿no le entiendo porque es estúpido, o es que el estúpido soy yo? La atribución de estupidez se realiza en medio del estupor, y por lo tanto, de una cierta estupidez propia, y de una cierta desesperación. Precisamente, cuando falta la honradez al respecto es cuando el recurso al insulto de la estupidez se convierte en la crueldad que a menudo tiñe el trato con los que no entendemos. Pero antes de llegar a la crueldad, el observa- 
dor mismo, o el observador dentro de cada uno de nosotros, puede advertir que la estupidez, a menudo, pertenece más a la situación misma que a los sujetos que se interrelacionan, y que quedan bañados por ella.

En medio de consideraciones semejantes, Musil concluye que el insulto es siempre una interrupción de la inteligencia, pues la pura racionalidad se limitaría a una explicación neutral del comportamiento del otro. Ello no quiere decir que la inteligencia, como tal, deba renunciar al insulto, o al menos, a la categoría de estupidez. A veces, justamente, no le queda otra, y lo único que puede hacer la inteligencia es reconocer lo inexplicable e interrumpirse a sí misma. Eso sí, sin dejarse llevar por la vertiente de la crueldad. Quizá, incluso, deba interrumpirse con cierto afecto y cuidado; con ese afecto positivo con el que a veces se llama "tonto" a una persona querida. En todo caso, y esto sería la conclusión de esas reflexiones iniciales, el recurso a la categoría de estupidez se da siempre en un momento de incomprensión o, más precisa y neutralmente, ante la opacidad que el otro nos ofrece. Es la forma más elemental de reaccionar cuando el otro se hace opaco, y no podemos ver sus motivos ni explicar sus intenciones: es una mancha gris que no podemos analizar desde nuestra visión del mundo. Hay, ciertamente, formas menos elementales de reaccionar: la angustia propia o la violencia agresiva hacia el otro, en todas sus posibles variedades. Pero esa condición elemental de la reacción que recurre a la estupidez, esa primera forma de hacerse cargo de la opacidad del otro y del atasco de la propia inteligencia nos puede dar unas claves decisivas para abordar la cuestión de lo propio y lo ajeno, la cuestión del sujeto.

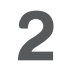

La opacidad del otro, la imposibilidad de ver sus razones -una opacidad que puede ser, como insinuamos, también respecto a uno mismo-, es, decimos, el elemento en que apelamos al recurso de la estupidez. Una estupidez que puede ser tanto propia como ajena. Quizá esto nos permita intentar una primera definición de estupidez, a pesar que hemos comenzado diciendo que es indefinible. En cierto modo, así lo hace el hegeliano Eduard Erdmann en su conferencia de 1866, setenta años antes de Musil. Parte, para ello, del siguiente ejemplo: una familia numerosa está en la sala de espera de la estación de Hamburgo, aguardando el tren para ir a una fiesta familiar a Kyritz, una pequeña ciudad de provincias cercana a Berlín. Y entonces:

[...] según iban entrando más viajeros en la sala, un muchacho joven, a todas luces un benjamín tardío [de la familia], iba perdiendo cada vez más su aspecto alegre y miraba casi miedosamente a todo el que llegaba: finalmente, cuando muy poco antes de la partida entró de golpe en la sala toda una muchedumbre, no pudo contenerse más: “Pero, ¿qué va a hacer toda esa gente en casa del abuelo de Kyritz?" Las car- 
cajadas de los hermanos mayores y la exclamación “¡Pero qué tonto!”, no tuvieron, por fortuna, consecuencias terribles. "Dejad en paz a mi tontito", dijo la madre, y le dio un beso en sus rubios bucles que tuvo el efecto habitual en este tipo de besos: el muchacho miró a su alrededor con la mirada radiante y cada rasgo de su bello rostro preguntaba: ¿no tenía yo razón?” (ERDMANN apud MUSIL, 2007, p. 89).

Valga esto como ejemplo ideal de estupidez: una estupidez inocente, cándida, que provoca las carcajadas, moderadamente despiadadas del "qué tonto", el beso cariñoso del "Mi tontito", y la satisfacción ingenua de quien ni siquiera se hace cargo de su error. ¿En qué consiste la estupidez de este chiquillo? Evidentemente, si el tren fuera a una gran ciudad, a Berlín, y, al llenarse de gente, y él hubiera dicho, ¿Pero, qué van a hacer todas esas personas en Berlín?, ello no parecería estúpido. Erdmann completa su aproximación con otro ejemplo menor: en un pueblo muy, muy pequeño, por el que estamos de paso, alabamos la belleza de unos ancianos robles ante un campesino del pueblo, y este dice: "O sea, que usted también se ha enterado ya de que el alcalde los va a talar". Compárese esto con que una situación en la que alabamos los plátanos de una gran ciudad, y un ciudadano responde "Es una indirecta sobre los planes de remodelación del alcalde, ¿no?” Uno y otro, el campesino y el ciudadano, ha dicho lo mismo, pero el primero podría ser un poco estúpido, mientras que el segundo, no. El campesino y el joven muchacho esperan que todos vean las cosas a través de su particular punto de vista, de su mundo de ideas - la casa del abuelo, las discusiones de aldea. En esto, en verdad, no son distintos del egoísta habitual, que mira por su propio interés y quiere llevar a los demás hacia él. Lo que nos hace considerarlos seres limitados, de mente estrecha, es que, además, parecen incapaces de concebir el mundo de otra manera que como ellos lo conciben: el niño no se imagina que alguien pueda coger el tren para otro fin que para ir a casa de su abuelo, como hace él; el campesino no se imagina que alguien pueda pensar en otras cosas que en las discusiones de aldea. Erdmann sugiere que cuando se multiplican los puntos de vista que uno puede concebir, uno se hace mas inteligente; lo cual podría ser discutible, si no se añade, además, una cierta capacidad para manejar esa variedad de puntos de vista ajenos. Pero sí que acierta, seguramente, cuando afirma que la persona se vuelve más estúpida cuando se reduce el número de puntos de vista y se estrecha su círculo visual, de manera que "llegamos a un punto en el que el radio de las ideas coincide con su centro, en que no es posible pensar ya una limitación mayor, un volverse todavía más estúpido" (ERDMANN apud MUSIL, 2007, p. 91). Habremos dado, entonces, con la forma nuclear de la estupidez, con la absoluta coincidencia de uno mismo con su propio punto de vista, ese punto central que Erdmann denomina - veremos luego si con razón - "el propio yo". 
El estúpido, entonces, es el que sólo es capaz de concebir el "propio" punto de vista, y nada más - como el joven en la estación. No en vano, los griegos llamaban al estúpido un "idiota", aquel que no tiene más visión o interés que lo "idio": lo propio de uno. Esa es su limitación. Es simple en tanto que no considera la complejidad posible de otros yoes, otros círculos y puntos de vista: en el extremo, y dado que un punto de vista siempre supone un cierto despegue del propio yo, el simple total sería "aquella persona para la que el propio yo fuera el único ojo de la cerradura por el que se puede mirar a ese rico salón que llamamos el mundo" (ERDMANN apud MUSIL, 2007, p. 92). La estupidez, entonces, será "aquel estado mental en que el individuo se considera a sí mismo y la relación consigo mismo como único criterio de la verdad y el valor; [...] en que lo juzga todo a partir de sí mismo" (ERDMANN apud MUSIL, 2007, p. 92, cursiva mía). Conviene insistir en que no se trata del egoísta moral -que muy bien puede ser consciente de cuáles son los intereses y puntos de vista de los otros, pero se cierra más o menos voluntariamente a ellos, en función de sus propios intereses-. Tampoco de lo que Kant llamaba un egoísta lógico ${ }^{5}$, que considera inútil comparar su juicio con el de los otros, pero sabe que hay otros juicios. Se trata de una incapacidad cognitiva, y práctica, para concebir otros puntos de vista posibles. Es una incapacidad, recuerda Erdmann, que no tiene que ver con una deficiencia mental, o con la falta de inteligencia. Pone, al respecto, el ejemplo del minerálogo que, estando en el campo, si le cae una piedra encima a un amigo, en lugar de socorrerle, exclamara “iEs un trozo interesantísimo de granito!" Podría ser un gran científico, pero no deja de ser tan tonto como el niño de la estación, o el campesino del pueblo.

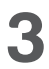

Ahora bien, la capacidad para imaginar otros puntos de vista distintos del propio, y por tanto, la capacidad para pensarse en el lugar del otro, es lo que Kant definía como Juicio o facultad de juzgar (Urteilskraft), ${ }^{6}$ una de las tres condiciones de la sabiduría, junto a la capacidad de pensar por sí mismo y la capacidad para pensar de modo consecuente. Tal como lo planteamos, entonces, el estúpido es el que carece de esa facultad, y no puede concebir que haya otros puntos de vista.

Ciertamente, Kant estuvo reflexionando sobre la noción de Juicio durante muchas décadas, y fue modificando de modo algo errático su concepción de ella. El libro de Mario Sgarba ${ }^{7}$ recorre esa reflexión y muestra cómo la sistematización última a la que llegó el Kant ya viejo en la Crítica del Juicio dista mucho de ser coherente. Las relaciones del Juicio con el sentido común, con la sabiduría y con la locura no llegan a ser unívocas. El loco, al que le falta el sentido común, o que ha 
perdido el Juicio, no es necesariamente un estúpido. Precisamente por eso, al loco solemos disculparle; mientras que al estúpido, no. Pero la discusión de esa distinción nos llevaría lejos de nuestro tema.

Kant, si no llega a dar una delimitación última de lo que entiende por esa facultad de juzgar, sí sabe que es la "desconocida raíz común de la sensibilidad y el entendimiento" (KANT, 1998, vol. II, A25, B29), de la razón cognoscitiva y de la razón práctica. No la da ni puede darla, por ser justo "desconocida" (MARZOA, 1987), pero sabe que es decisiva en toda la economía transcendental de la razón. La define como la capacidad para pensar un concepto universal a partir de una instancia particular dada, sin disponer de una regla para ello. En esa medida, el Juicio es, sobre todo, una capacidad de universalización, de abstraer desde lo particular y concreto hacia una perspectiva más general. Precisamente por eso, funciona íntimamente ligado a la imaginación, al libre juego de las facultades que puede producir nuevos conceptos con los que categorizar y entender el mundo. Ello supone un movimiento reflexivo (se trata, no en vano, del juicio reflexionante) por el que uno se aparta de las "condiciones privadas y subjetivas del juicio, en las que tantos se hallan atrapados [eingeklammert], y reflexiona sobre su propio juicio a partir de un punto de vista universal (que él sólo puede determinar en tanto que se pone en el punto de vista de otros)" (KANT, 1974, vol. X, p. 225). Es decir, el juicio, a la vez que concibe la pluralidad de los otros, sitúa a quien lo tiene en un punto de vista general, lo saca de su propia particularidad.

En virtud de qué se produce ese salto a la universalidad es uno de los misterios que deja a Kant a las puertas del irracionalismo. Como la facultad de juzgar es lo que permite espontáneamente producir conceptos, reglas de construcción, discursos, no es posible hacer discursos y conceptos sobre ella. La raíz común tiene que permanecer necesariamente oscura (MARZOA, 1987, p. 37). Misteriosa o no, la ausencia de una explicación precisa de cómo se realiza el salto a la universalidad - o la salida de la particular subjetividad - es la condición misma del Juicio: si hubiera una explicación, ya no se trataría del juicio reflexionante, sino que se estaría siguiendo una regla; y aun así, queda siempre el juicio como aquello que nos capacita para seguir reglas y está, por lo tanto, más allá de ellas.

Kant ni siquiera tiene claro si esa capacidad del juicio se adquiere como resultado de un proceso educativo o si, en tanto que es parte constitutiva de la psique humana, no es adquirible ni enseñable. A veces, opta por insistir en lo último, o afirma que la facultad del juicio, que no se puede aprender, sólo se la llega a alcanzar muy tarde ${ }^{8}$. Lo cual viene a concordar con la común idea de que los estúpidos lo son de nacimiento: "El idiota nace, y el loco se hace", decía Jean Paul (2012, p. 107). Pero a veces Kant considera que, en la medida en que los enunciados del 
juicio son objeto de discusión y de modificación - por ejemplo, los enunciados del gusto - el juicio sí se puede educar. ${ }^{9}$ Entronca así con una tradición - en última instancia, toda la tradición humanista - para la que el Juicio, la capacidad de universalización, se puede enseñar: constituye, de hecho, el proceso mismo de educación. En efecto, en la tradición clásica alemana de la que Erdmann no deja de ser un heredero menor, la Bildung, el proceso de educación y formación, se define como el ascenso a la universalidad (la universalidad del saber científico, pero también la universalidad del cosmopolitismo y del saber mundano práctico en el trato con los otros) por el que, tras un proceso largo de experiencias de extrañamiento superadas con éxito, el sujeto va abandonando su lugar inicial, provinciano y primitivo, completamente unilateral, y adquiere la capacidad de mirar desde el punto de vista de otros. Además, el resultado de ese proceso de formación es, justamente, el tener una subjetividad propia.

La persona formada y madura, no sólo es capaz de universalizar sus máximas morales (y este sería solo el lado ético de la formación), sino que tiene la amplitud de miras suficiente como para concebir puntos de vista y actitudes completamente diferentes de los propios.

Hay, en todo caso, tres elementos en la facultad de juzgar tal como la hemos expuesto - al margen de su carácter misterioso o irracional, en el que ahora no podemos entrar - que atañen a su vinculación con la estupidez o falta de ella, tal como la hemos definido con Erdmann. La tesis de este ensayo es que el examen de esos tres elementos y de sus consecuencias nos permite, por un lado, saber algo más de la estupidez y, por otro y sobre todo, localizar en ella una paradoja que, según intentaré mostrar, concierne a la constitución de la subjetividad misma.

1) La capacidad de juzgar consiste en poder producir un concepto general separado, o abstraído, de la instancia particular dada. Esa capacidad de universalización permite, por eso mismo, apartarse del punto de vista propio y adoptar imaginariamente - siempre imaginariamente, y nunca de modo real - el punto de vista de los otros. Pues el punto de vista general no tiene un contenido concreto, sino que es la posición reflexiva, imaginaria, desde la que se puede concebir el propio punto de vista como uno más entre los otros, y concebir los otros también. Por ejemplo: concebir que los otros están en la estación y cogen el tren para ir a sitios distintos del que voy yo, cosa que el niño del ejemplo no parece capaz de hacer. Llamamos estúpido, por eso, a quien percibimos atado a su particularidad subjetiva.

2) El movimiento de universalización, o de encontrar un concepto general para una instancia particular, no es una operación lógica. Tampoco es un movimiento de la moral. Aunque la moral puede exigirlo, también puede, en el 
sentido kantiano, convertirse, como deber, en universalidad abstracta que ignora toda individualidad particular, que puede existir sin ellas e incluso contra ellas. De hecho, el rigor moral puede ser también, en determinadas situaciones, y cuando menos, una figura excelente de estupidez. El juicio y la capacidad de imaginar el lugar de los otros tiene que ver más bien con el tacto, con la sensibilidad, con un saber práctico capaz de encontrar lo que hay que hacer en una situación determinada cuando no está dada la regla para ello. La universalidad que produce el juicio no es una sustancia objetiva, aunque etérea, como haber llegado a un nivel superior donde se ordenan los conceptos. Antes bien, el juicio se aplica de modo pragmático - para hacer lo que se debe en una situación concreta, para calificar algo como bello-, sin abandonar nunca el plano de lo concreto y particular. Lo universal del juicio es una producción reflexiva, especulativa, de la imaginación, por la que somos capaces de comprender de una manera general - esto es, que contiene nuestro punto de vista y el del otro - una situación particular concreta, y actuar según esa comprensión. La falta de tacto, que con frecuencia identificamos como estupidez, consiste en no percibir - incluso, no percibir físicamente - la posición del otro.

3) La adquisición de la facultad de juzgar, o al menos, de una habilidad creciente para concebir un punto de vista general, es el proceso de educación del individuo y equivale, por tanto, a un proceso de subjetivación. Erdmann, ateniéndose al optimismo humanista que todavía podía ser dominante en el siglo XIX, plantea que la estupidez, como todo vicio, puede ser enmendada, pues "todos nosotros nacemos estúpidos y rudos, solo la vida nos sazona y pule". La tosquedad inicial, que en el niño se da como ingenuidad, va adquiriendo refinamiento conforme el chico crece y pasa por las pruebas de la vida que, a fuerza de golpes o de encuentros, le van haciendo a uno menos estúpido. Bien es verdad que siempre quedan restos de esa estupidez originaria, que nunca dejamos de hacer tonterías cuando menos lo esperamos de nosotros mismos, y que a veces llega, dice Erdmann, hasta la mayor de ellas: considerar inaceptables todas las otras estupideces, todas las tonterías de los otros. Es entonces, seguramente, cuando uno se vuelve cruel con los estúpidos, en una especie de hybris de la que los hermanos mayores de nuestro ejemplo son una buena muestra. Mientras que, en cambio, la aceptación de la propia estupidez, de lo que resulta una tolerancia benevolente hacia la estupidez ajena, puede ser uno de los grados más altos de inteligencia. 


\section{4}

Hay razones para desconfiar de ese optimismo ilustrado sobre la paulatina eliminación de la estupidez por medio de la educación que recorre el ensayo de Erdmann. Podría desconfiarse, incluso, de la desconfiada honradez con la que él mismo sabe que un reducto de estupidez es imborrable en cada individuo. El ensayo de Musil, setenta años posterior, producido en pleno auge del nazismo y crisis de entreguerras, mucho más ácido y agudo, pero menos sistemático, es hijo de esa desconfianza. Parece, más bien, que la estupidez no se cura, ni disminuye, con la educación, ni con la civilización. La tarea de juzgar entre el punto de vista propio y la imaginación de las posiciones ajenas se mantiene en todas las etapas de la vida y en todas las etapas de la historia. No obstante, es posible que algo de esa aspiración humanista e ilustrada estuviera en el fondo del sorprendente diagnóstico que hizo Hannah Arendt del nazismo, con él, de la evolución del mundo moderno.

Resumidamente, Arendt venía a decir que uno de los efectos de la modernidad, al destruir las tradiciones y dejar a los hombres sin guías de orientación posibles, vale decir, sin reglas, había sido el de poner a las personas ante la tarea de "pensar sin barandillas". El fracaso de la cultura moderna, y en particular, de la cultura alemana, consistía en esa incapacidad de la mayoría de las personas, incluso las supuestamente cultas y preparadas, para pensar sin barandillas, para saber cómo juzgar y cómo actuar cuando no hay ya unos patrones de conducta fijos y establecidos. En esas circunstancias, alguien como Eichmann - que es el ejemplo ya clásico para este diagnóstico- se limitaría supuestamente a cumplir órdenes y a seguir acríticamente las instrucciones de sus superiores, o de las circunstancias mismas, sin pararse a discurrir sobre el significado de sus acciones. La maldad de Eichmann no era depravación (wickedness), ni siquiera era del tipo de los que tienen mala conciencia - pues de hecho, sólo las buenas personas pueden tener mala conciencia, como oportunamente observa Arendt. Su maldad procedía de no tener conciencia en absoluto, y esta, a su vez, de una incapacidad de reflexión que obedecía a una "curiosa y absolutamente auténtica incapacidad para pensar" (ARENDT, 2003, p. 160). La incapacidad para pensar no es necesariamente estupidez; de hecho, Arendt especifica claramente que ella no lo considera tal, sino más bien "superficialidad" (shallowness), una actitud de adhesión a lo convencional, al cliché y la frase hecha cuya principal función parecía ser la protección frente a la realidad. Como tal, puede ir aparejada con la inteligencia, y de hecho, "hay gente muy inteligente que no ha pensado nunca nada" (ARENDT, 2003, p. 164). Ahora bien, la incapacidad para pensar sí va asociada con el no poder disociarse de sí mismo, del propio yo, y ello tiene, entre otras, la fatal consecuencia de anular la 
conciencia moral y, por ende, la potencia crítica sobre el acontecer del mundo, o de las propias acciones. Es decir, va asociada con una cierta inconsciencia, y una inconsciencia culpable. Salvo en el caso, añadiríamos, de los niños, donde se trata más bien de ingenuidad.

Por otro lado, si el pensamiento tiene lugar en un ámbito invisible, "fuera del mundo", cuando uno está a solas consigo mismo, el efecto tangible del pensar, continua Arendt, es el juzgar: la capacidad para tratar con "particulares sin subsumirlos bajo reglas generales que se enseñen y se aprenden". Y es esta facultad de tratar con particulares sin someterlos a un canon de reglas generales, determinantes, lo que, a juicio de Arendt, le faltaba a Eichmann y, por extensión, al hombre moderno. Y le faltaba por no haber pensado. Desprovisto de patrones de conducta en un mundo que ha arrambla con todo lo anterior y se transforma sin lógica ni sentido aparentes, y desprovisto también de una facultad de juzgar que le permita proporcionar significado general (que englobe, por ello, las perspectivas de otros, por ejemplo, las víctimas) a las monstruosas situaciones en las que se ve implicado, Eichmann renuncia al juicio y se limita a cumplir unas instrucciones al pie de la letra. En definitiva, es el hombre gris, anónimo, marioneta en los engranajes de la convención social, carente de criterio propio y fácil de conducir en la masa.

De un modo más trágico, puesto que fue víctima directa de ello, el teólogo Dietrich Bonhoeffer se quejaba directamente de la estupidez de su compatriotas, entregados ciega y acríticamente a Hitler. Hay ciertas circunstancias en las que los hombres se dejan convertir en estúpidos, dejándose fascinar por la "ostentación exterior de potencia, política o religiosa". El "problema de los estúpidos", dice Bonhöeffer (y la expresión es suya), es que defecto no afecta a su intelecto, sino a su propia humanidad. No es un problema cognitivo, ni tampoco moral. Ni siquiera son malos - pues contra el mal es posible al menos protestar, oponerse a él -, sino que estamos indefensos frente a ellos, pues "no le dan crédito a los hechos que están en contradicción con los prejuicios personales - en estos casos, el estúpido se vuelve incluso escéptico - [...]. De este modo, el estúpido, a diferencia del malvado, se siente completamente satisfecho consigo mismo, [...] e intentar persuadirlo con argumentos es algo sinsentido y peligroso". ${ }^{10}$ Son gente sin independencia interior, a pesar de su tozudez, que repiten eslóganes y tópicos, sin contacto con la realidad por haberse fiado ciegamente a un poder superior. Sobre ellos, más que sobre criminales patológicos, se asentaba el nazismo, como vio el teólogo Bonhoeffer según avanzaba la guerra y la catástrofe alemana.

De un modo menos trágico, puesto que pudo escapara ello, Arendt diagnostica lo mismo, al igual que otros críticos de la cultura contemporáneos suyos, como enfermedad del hombre contemporáneo. Por su incapacidad para juzgar, para adop- 
tar un punto de vista general, para discutir y deliberar, por ello mismo, viene a ser un trasunto del estúpido del que hemos venido hablando. En cierto modo, no tiene la fijación en la perspectiva del propio yo que planteábamos como definición de la estupidez; sino que es más bien una renuncia al yo, o a su propia subjetividad. Por otro lado, esa renuncia se ve compensada por la obsesión con la privacidad - afianzada en una sociedad concebida como juego y negociación de intereses particulares - que se ha instalado en la evolución de las sociedades contemporáneas.

No se trata, en ningún caso, de diagnosticar sin más la modernidad como un tiempo estúpido. Ya hemos insinuado que el estado de estupidez, la opacidad que nos desconcierta y que hemos tratado de identificar como estrechamiento de los puntos de mira, puede darse en cualquier situación humana y en cualquier época. Lo que este excurso arendtiano pone más bien de manifiesto es que el déficit de reflexividad comporta un debilitamiento de la realización subjetiva, y que esto, en efecto, se hace más patente en una cierta época: precisamente aquella que, por otro lado, multiplica los puntos de vista posibles. Pero la multiplicación de los puntos de vista posibles no significa que los sujetos que tienen ante sí esos puntos de vista vayan, en efecto a ser capaces de imaginar puntos de vista ajenos. Puede ocurrir que sigan considerando esos puntos de vista, en toda su variedad, como propios, y se mantengan incapaces de concebir un punto de vista verdaderamente ajeno. Por eso, en las sociedades cosmopolitas, con todo su refinamiento, se encuentra un tipo de estúpido para el que una persona bien asentada en su tierra, pero con capacidad de juicio, sólo encontraría risas.

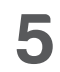

Conviene señalar que no se trata de aumentar el número de puntos de vista de que se dispone; sino de madurar la capacidad para imaginar puntos de vista ajenos. De hecho, un habitante del mundo occidental de hoy, por ejemplo, conoce muchas más costumbres y modos de vida que alguien de hace cien años; incluso puede haberlos integrados en su propia vida cotidiana: culinariamente, por ejemplo. Frente a la monotonía de las cocinas nacionales hace una década todavía, está la variedad cosmopolita a la que cualquiera tienen hoy acceso en un pasillo de supermercado. Pero eso no significa que el de hoy tenga más capacidad de imaginar puntos de vista ajenos, ni siquiera que sea más tolerante en el gusto de lo que lo eran sus antepasados. Aunque se está, seguramente, en mejores condiciones de serlo. Por eso, no es sólo una cuestión de "aumentar nuestro vocabulario", como diría Rorty. Es posible conocer muy bien lenguas y, no obstante, ser un perfecto idiota. 
Ahora bien, el proceso de construcción de la subjetividad como un aumento de la capacidad para imaginar puntos de vista distintos del propio particular no debe entenderse como una construcción progresiva y firme, que va asentando un piso sobre otro. Algo de esa ilusión podía estar en la visión más ingenua de la Ilustración y del progreso; pero en la propia tradición humanista clásica de la Bildung, Erdmann, y todos los autores que tratan el tema, están de acuerdo en que ni el más experimentado y maduro sujeto puede creerse a salvo de volver a hacer el tonto en cualquier momento, de cometer una estupidez. Y, huelga decirlo, la mayor estupidez sería creerse que efectivamente uno está a salvo de eso. Esta persistencia del riesgo de hacer el tonto la formula Erdmann como un resto ${ }^{11}$ irreductible de estupidez que nos queda, desde nuestra tosquedad original previa a la educación, y que siempre puede manifestarse de nuevo. Pero, probablemente, no es tanto un resto - algo que ontológicamente formase parte de nuestra identidad - como una disposición permanente, en virtud de nuestra falibilidad a la hora de aplicar el Juicio, y de las circunstancias de la situación misma. En medio de un caos aeroportuario, en una situación política compleja o en una historia sentimental mínimamente enrevesada, es casi imposible no cometer una u otra estupidez, no acabar haciendo el idiota; incluso si uno es el sujeto más reflexivo del mundo, y más considerado hacia las perspectivas ajenas.

Esta posibilidad permanente de lo que llamamos estúpido señala, desde luego, la falibilidad y la contingencia de los sujetos. Pero indica también, y esa es la meta de este artículo, que la relación entre estupidez y subjetividad no es lineal, sino que tiene, cuando menos, una doble vertiente de la que resulta una paradoja.

Para empezar, ocurre que, por mucho que la despreciemos, hay un placer estético en la estupidez cuando la observamos. Al final de su conferencia, Erdmann repara en que nos divierte a veces encontrar una persona tonta, no sólo por la crueldad del insulto a que nos referíamos antes. Nos divierte y nos enternece, como el niño a la madre que le dice "Mi tontito". Cuando repara en ese placer, Erdmann lo atribuye, en parte, a que vemos allí la patria primitiva de donde venimos, nuestra infancia, aquello que fuimos en nuestra primera ingenuidad, y que siempre retorna. En parte es así, sugeriré, pero no por que la última idiotez que hemos cometido nos ponga risueñamente ante los ojos una foto de nuestra niñez. Veremos que, más que poner ante los ojos, nos hace tener una experiencia directa, no necesariamente placentera, de auténtica individualidad. Y en el caso de la propia estupidez, una experiencia de nosotros mismos.

No es la crueldad, ni tampoco es la alegría por ver la ingenuidad primitiva, la frescura del origen. Tampoco, habría que decir, es el placer de estar sacando provecho de algo, de volverse uno más inteligente al contemplar la estupidez. Aunque 
siempre haya algo de eso. Erdmann intuye que esta alegría estética llega, sobre todo, por lo que tiene la estupidez de algo único, inimitable e irrepetible, de absoluta individualidad. Llamamos estúpido, dice, a aquel cuyo cosmorama o agujero de la cerradura por el que mira el mundo, su horizonte, tiene un diámetro cero, y subsume todas las cosas bajo el punto de vista único de su propio yo: existe solo una vez. En su tosquedad, es original: lo que tenemos aquí es el placer que proporciona todo lo individual y único.

Por supuesto, aprendemos mucho de quienes han visto mucho mundo, y tienen gran cantidad de puntos de vista. Pero, tras ellos, y mejor que los casos intermedios, están aquellos que sostienen un único punto de vista, las personas originales: y puede ocurrir que quien se alimenta de una única idea nos resulta más provechoso que el muy inteligente. Nada amplia tanto nuestro horizonte visual como mirar dentro de un agujero verdaderamente estrecho.

O nada nos permite tanto ampliar nuestro punto de vista como pasar por un punto de vista único, irrepetible: aquel que no puede abstraerse en una reflexión. Y eso es lo que contemplamos en otro, de manera directa al contemplar tipos originales, incapaces de adoptar la perspectiva de otro: topamos ahí con una individualidad extrema que es la alteridad de otro. Pues todo aquel cuyo punto de vista somos capaces de reproducir o de proyectar de alguna manera en un juicio general, corre el riesgo con eso de quedar, en tanto que comprendido, anulado en su individualidad. Las personas que, como se dice en castellano, se pasan de listas comenten con frecuencia el vicio de anular la individualidad del otro al pretender interpretarlo con un acto de violencia hermenéutica.

En la opacidad del otro, que calificamos como estupidez, está también su irrepetibilidad, su condición de ser absolutamente único, su individuación. El sí-mismo, el sujeto que él es. Llegamos así a la paradoja de la estupidez: por un lado, la estupidez disminuye al subjetivizarse el individuo, conforme este es capaz de aumentar los puntos de vista, de formarse. Desestupidización equivale a subjetivización, y eso es un proceso formativo. Por otro lado, el individuo puro e irrepetible lo encontramos en el estúpido absoluto, que no tiene más perspectiva que el irrepetible propio yo. O bien, formulada de otro modo, la estupidez se da en el sujeto anónimo y gris, que no tiene un Juicio propio, y se da en el sujeto máximamente original, en el que es muy suyo. Ciertamente, no se trata de una contradicción irresoluble, sino que la paradoja resulta de la forma doble de nuestra constitución subjetiva. Por un lado, la subjetividad es un logro, aquello que cada uno alcanza según se va haciendo y formando, y es un logro propio ${ }^{12}$; pero, a la vez, ese trabajo de autoformación se hace ese nudo irreductible que es la estupidez que cada uno es, según lo descubre Erdmann. 
Podemos concluir el texto profundizando un poco más en la paradoja. Está el punto de radio cero - el del niño del ejemplo -, que coincide con el propio yo. Es un punto de máxima estupidez donde el yo ni siquiera se distingue de sí mismo y no tiene conciencia de sí. A la vez, es el de máxima opacidad del otro, el nudo en el que nos encontramos con el sí-mismo del otro sin mediaciones ni interpretaciones, que son siempre formas generales de juicio, atribuciones universales que pretenden iluminarlo. Pero allí donde el otro sólo nos ofrece su opacidad - y ya hemos visto, con Musil, que utilizamos el insulto de "estúpido" como una posible reacción a su opacidad -, allí donde se muestra incomprensible, es donde le aceptamos como único e irrepetible. Ya sea por afecto (como la madre al hijo en nuestro ejemplo, o como entre amigos y amantes, que justo por eso se toleran mutuamente las "tonterías", y se ríen de ellas), ya sea porque dejamos de interpretarlo y optamos por una distancia que mantenga la convivencia.

Hacia sí-mismo, en primera persona, reflexivamente, ese punto de radio cero es también el punto en el que nos reconocemos. Precisamente en el error que siempre repetimos, en la tontería que siempre hacemos, es donde nos vemos muchas veces a nosotros mismos y nos decimos, con un lamento: ese soy yo. Teológicamente, esto se explicaba como el pecado original que cada uno lleva y le hace único ante Dios, le individualiza, por tanto. Estoy sugiriendo que lo mismo pasa con la estupidez: uno es capaz de reconocer su propia estupidez, aquello de lo que no puede despegarse, o la piedra en la que siempre tropieza, y entonces ha dado consigo mismo. Pero ya sabemos que esto requiere un grado alto de pensamiento y autorreflexividad.

Por eso, lo contrario del punto de radio cero, el espacio de mayor amplitud, el que es capaz de recoger mayor número de puntos de vista puede corresponder a nuestra subjetividad madura, pero nunca puede borrar ese momento de la propia estupidez. La adquisición de nuevos puntos de vista nos forma hacia fuera, y nos permite construir el sujeto que ofrecemos al mundo en el intercambio intersubjetivo, y nos forma hacia dentro - en lo que podemos dar cuenta de nosotros mismos -; pero sólo lo hace recogiendo el nudo irreductible que es la propia estupidez: en un lenguaje más clásico, sólo en cuanto somos conscientes de nuestra propia falibilidad.

Desde el niño tontito que no puede concebir que otros vayan en tren a otro sitio que la casa de su abuelo, hasta el sujeto maduro y formado que aprendido a aceptar su propia limitación, a asumir su inevitable estupidez y aceptar la ajena, hay un largo proceso de formación. El sistema educativo, la labor de unos maestros que pulen la tosquedad inicial y aportan puntos de vista, ocupa gran parte de él. Pero no está en el primer paso, ni en el último. 


\section{The stupidity paradox}

\section{Abstract}

This essay explores the connection between the stupidity phenomenon and the subjectivity construction in the educational formation process. From the reading of two classical essays about the stupidity, written by Robert Musil and Eduard Erdmann, is established the paradox character of the stupidity. On one hand, it is equivalent to the incapacity of adopting different points of view about itself, and, in what regards it, may be corrected by the process of the Bildung, that is the acquisition of the judgment faculty and, from that, the capacity of building an own subjectivity. This judgment, specially, requires these points of view from the outside as it appears, with notable political and critical implications in Hannah Arendt's work and in Kant's third Critic. On the other hand, the stupidity is a practical concept of the intersubjective relations that correspond to the opacity of the others conduct, but also, and specially, the stupidity concerns about the inner and irreducible circle of each subjectivity: that one that can't be covered by any judgment. Thus, the stupidity has a paradoxical relation in the subject constitution and this paradox must attend the education.

Keywords: Subjectivity. Education. Stupidity. Bildung.

\section{Notas}

1 Este trabajo se desarrolla en el marco del proyecto de investigación "Encrucijadas de la subjetividad: experiencia, memoria e imaginación” (FFI2012-32033), financiado por el MEC del gobierno de España.

2 Los dos ensayos son el muy célebre de Robert Musil, Über die Dummheit: Vortrag auf Einladung des österreichischen Werkbunds. Gehalten in Wien am 11. und wiederholt am 17. März 1937; y el de Eduard Erdmann, Über die Dummheit, Vortrag im Wissenschaftlichen Verein in Berlin, gehalten am 24. März 1866. Ambos están reunidos y traducidos al castellano (MUSIL, 2007), con un prologo de Félix Duque y una introducción de Roland Breeur.

3 También se puede calificar de estúpida una situación, como he dicho, independientemente de las personas implicadas en ella, o incluso un objeto, en el sentido en que decimos que un aparato, por ejemplo, es estúpido, por su diseño, por su escasa funcionalidad, o por su consumo. Pero dejo de lado estos casos, pues no nos interesa aquí tanto la estupidez en su relación con la subjetividad.

4 O quizá, mejor, una vez que lo hubiéramos explicado, si quisiéramos introducir aquí la vieja dicotomía explicación-comprensión, entre Erklären y Verstehen. Pues la explicación sí es neutra; la comprensión, ya no, y puede estar teñida de un tono afectivo. Piénsese en la relación del profesor y el alumno,o de los padres y los hijos, o entre amigos, o en el amor. Las relaciones afectivas son también relaciones de conocimiento: y también en ellas se llama tonto al otro, ya con cierto cariño, como veremos en un ejemplo de Erdmann más adelante.

5 "El egoísta lógico no tiene por necesario probar su juicio en el entendimiento de otros, qomo si no necesitase de esta prueb externa (criterium veritatis externum)" (KANT, 1998, p. 409).

6 Me atengo aquí a la convención de escribir "Juicio" para la facultad de juzgar, Urteilskraft, y "juicio" para Urteil.

7 Véase, al respecto, Mario Sgarba (2011).

8 No antes de los sesenta años, y solo unos pocos, dice en la Antropología, loc. cit. p. 511.

9 Véase el análisis de Oscar Cubo (2012, p. 186 et seq.). Si el juicio de gusto kantiano es una invitación a compartir nuestra apreciación de lo bello, debe presuponer una modificabilidad en el juicio de los otros, y, por lo tanto, su capacidad de ser educados. Pero esto es, como el propio, Cubo observa, sólo una de las posibles lecturas de Kant.

10 Vid. el escrito de Bonhoeffer "Diez años después. Un balance al final de 1943", publicado solo después de la guerra, puede verse en Resistenza e resa. Lettere e scritti dal carcere (BONHOEFFER, 1988). Una exposición más detallada de la posición de Bonhoeffer y de las consecuencias políticas de los ciudadanos estúpidos puede verse en Valentina Pazé (2013). 
11 Aun después de la formación, de la Bildung, "quedan en cada uno de nosotros más o menos partes sin pulir, restos de esa estupidez originaria que dura hasta que cometemos la mayor de ellas: considerar inaceptables todas las otras" (ERDMANN apud MUSIL, 2007, p. 100).

12 Hay muchos modos de exponer ese camino de constitución de la subjetividad. He empezado a exponer la perspectiva hegeliana en "What does 'not to be bound to life' mean? Subjectivity and Recognition in Hegel” en Hegel Studien (en prensa). Pero podría seguirse aquí también la Hermenéutica del sujeto de Foucault (2001) y su idea del cuidado de sí.

\section{Referências}

ARENDT, H. Responsibility and judgement. New York: Schocken, 2003.

BONHOEFFER, D. Resistenza e resa. Lettere e scritti dal carcere. Cinisello Balsamo: Edizioni San Paolo, 1988.

BOXEL, M. von. Enciclopedia de la estupidez. Síntesis: Madrid, 2003.

CUBO, O. Sentido común y subjetividad. Madrid: Plaza y Valdés, 2012.

FOUCAULT, M. Hermeneutique du sujet. Paris: Gallimard-Seuil, 2001.

KANT, I. Werkausgabe in zwölf Bände. Ed. por Weischedel. Frankfurt am Main: Suhrkamp, 1974.

MARZOA, F. M. Desconocida raíz común. Estudio sobre la teoría kantiana de lo bello. Madrid: Visor, 1987.

MUSIL, R. Sobre la estupidez. Madrid: Abada, 2007. . Über die Dummheit. Berlin: Alexander Verlag, 2011.

PAUL, J. Elogio de la estupidez. Madrid: Cómplices, 2012.

PAZÉ, V. En el nombre del pueblo. El problema democrático. Madrid: Marcial Pons, 2013.

SGARBA, M. Crítica del juicio de Kant. Madrid: Maia, 2011. 